\title{
(6) OPEN ACCESS \\ Risk of solid cancer in patients exposed to anti-tumour necrosis factor therapy: results from the British Society for Rheumatology Biologics Register for Rheumatoid Arthritis
}

\author{
Louise K Mercer, Mark Lunt, Audrey L S Low, William G Dixon, Kath D Watson, \\ Deborah P M Symmons, Kimme L Hyrich, BSRBR Control Centre Consortium
}

\begin{abstract}
Handling editor Tore K Kvien
- Additional material is published online only. To view please visit the journal online (http://dx.doi.org/10.1136/ annrheumdis-2013-204851).

Arthritis Research UK Centre for Epidemiology, Centre for Musculoskeletal Research, Manchester Academic Health Science Centre, The University of Manchester, Manchester, UK
\end{abstract}

\section{Correspondence to} Dr Kimme L Hyrich, Arthritis Research UK Centre for Epidemiology, The University of Manchester, Stopford Building, Oxford Road, Manchester M13 9PT, UK; Kimme.hyrich@ manchester.ac.uk

Received 31 October 2013 Revised 24 February 2014 Accepted 1 March 2014

Published Online First

31 March 2014

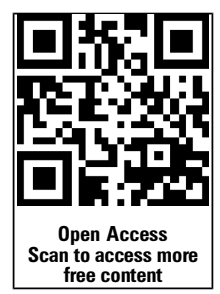

CrossMark

To cite: Mercer LK, Lunt M, Low ALS, et al. Ann Rheum Dis 2015;74:1087-1093.

\section{ABSTRACT}

Background Patients with rheumatoid arthritis (RA) have an increased risk of certain solid cancers, in particular lung cancer, compared to the general population. Treatment with tumour necrosis factor (TNF) inhibitors (TNFi) may further enhance this risk.

Objectives To compare the risk of solid cancer in patients with RA treated with TNFi to that in patients treated with non-biologic (synthetic) disease modifying antirheumatic drugs (sDMARDs).

Methods Patients with a physician diagnosis of RA enrolled in the British Society for Rheumatology Biologics Register, a national prospective cohort study established in 2001 to monitor the long-term safety of TNFi, were followed via record linkage with the national cancer registries until first solid cancer, death, for 5 years, or until 2011. Rates of solid cancers in 11767 patients without prior cancer who received TNFi were compared to those in 3249 patients without prior cancer treated with sDMARDs.

Results 427 solid cancers were reported in 52549 patient-years follow-up for the TNFi group (81 (95\% Cl 74 to 89 ) per 10000 patient-years) and 136 cancers were reported in 11672 patient-years in the sDMARD cohort (117 (95\% Cl 98 to 138) per 10000 patientyears). After adjusting for differences in baseline characteristics there was no difference in risk of solid cancer for TNFi compared to sDMARD treated patients: HR 0.83 (95\% Cl 0.64 to 1.07). There was no difference in the relative risk of cancer for any of the individual TNFi drugs.

Conclusions The addition of TNFi to SDMARD does not alter the risk of cancer in RA patients selected for TNFi in the UK.

\section{INTRODUCTION}

Tumour necrosis factor $\alpha$ (TNF) plays a complex role in the development and progression of tumours. ${ }^{1-4}$ From early in the development of TNF inhibitors (TNFi), there was concern that their use might lead to an increased risk of malignancy in patients with rheumatoid arthritis (RA). Patients with prior malignancy were therefore excluded from the majority of TNFi randomised controlled trials (RCTs). An early meta-analysis of RCTs fuelled concerns that TNFi may increase the risk of cancer, when it reported an almost fourfold increase in solid cancers in patients treated with infliximab (INF) or adalimumab (ADA) versus placebo. $^{5}$ Although a number of subsequent meta-analyses have not replicated the finding, ${ }^{6} 7$ concerns have persisted. Few long-term observational studies have reported on the risk of solid cancer following TNFi use, and no association with an overall increased risk of cancer has been found. ${ }^{8-12}$

The primary aim of this study was to determine the incidence of solid cancer in people with RA treated with TNFi, and to compare this to the incidence in biologic-naïve patients treated with nonbiologic (synthetic) disease modifying antirheumatic drugs (sDMARDs). Additional aims were: (i) to examine and compare, where possible, the sitespecific risk of solid cancer; and (ii) to compare the survival following diagnosis of solid cancer in patients treated with TNFi versus sDMARDs.

\section{METHODS}

\section{Patients}

Patients were participants in the BSRBR-RA, a national prospective cohort study established in 2001 to examine the long-term safety of biologic therapy in RA. Patients starting treatment with one of the first three available TNFi (etanercept (ETA), INF and ADA) were recruited from across the UK. UK guidelines recommend that TNFi use is restricted to patients with active disease (28 joint disease activity score $\left.(\text { DAS28) })^{13}>5.1\right)$ despite treatment with at least two sDMARDs, one of which should be methotrexate. ${ }^{14}$ A comparison cohort of biologic-naïve RA patients, with active disease despite current treatment with sDMARDs (guideline DAS28 $\geq 4.2$ ), was recruited from 28 sites. ${ }^{15}$ The subjects' written consent was obtained.

\section{Baseline}

Baseline data collected via nurse-completed questionnaire included age, sex, RA disease duration, DAS28, current and past sDMARDs, baseline glucocorticoid use, co-morbidities and smoking history. Patients completed a Stanford Health Assessment Questionnaire $(\mathrm{HAQ})^{16}$ to indicate level of physical disability and were asked to select their ethnic group from a list. Previous malignancies, including date and site, were identified via record linkage with the National Health Service Information Centre (NHS IC) and the Northern 
Ireland Cancer Registry. Capture of cancer cases is very high using these sources, for example $97 \%$ for cancers occurring in England in 2009. ${ }^{17}$

\section{Follow-up and outcome}

All patients were followed in identical manner. Changes to RA therapy were reported on nurse-completed questionnaires 6-monthly for 3 years then annually thereafter. Data on adverse events (including cancers) were captured in three ways: nursecompleted questionnaires; 6-monthly patient health diaries (first 3 years only); and by flagging with the national cancer agencies which reported malignancies using the 10th edition of the International Classification of Diseases (ICD-10). The primary outcome measure was the first verified solid cancer per subject. Solid cancers comprised all cancers except lymphoproliferative or myeloproliferative malignancies and keratinocyte skin cancers. Additional information (including histology) was sought from physicians for all reported cancers, using a standardised proforma. Cancers were verified if they were either confirmed on a histology report or reported by a national cancer agency.

\section{Statistical analysis}

The analysis included patients with a physician diagnosis of RA who had at least one returned nurse-completed follow-up questionnaire by 31 January 2011 (figure 1). The TNFi cohort comprised patients who received ETA, INF or ADA as their first biologic therapy with or without concomitant sDMARDs and who had been registered within 6 months of starting treatment. Patients with a diagnosis of solid cancer reported by a national cancer registry prior to TNFi initiation (or study registration in the sDMARD cohort) were excluded. The first 6 months of follow-up time was excluded from both cohorts, to minimise selection bias. Patient-years of follow-up time were calculated from 6 months after the date of starting a TNFi, or 6 months after the date of registration for the sDMARD cohort. Follow-up was censored at the date of diagnosis of the first solid cancer, death, after contributing 5 years of follow-up to the analysis (excluding the first 6 months), or on 31 January 2011, whichever came first. Patients in the sDMARD cohort who subsequently started a biologic drug contributed follow-up time until the first dose of biologic therapy, and subsequent follow-up time to the TNFi cohort if they consented to be re-recruited and the cohort was still recruiting.

Rates of cancer are presented as total events per 10000 patient-years with 95\% CIs. Risk comparisons were made between the TNFi and sDMARD cohorts using Cox regression. Potential confounders were identified a priori and comprised: age; sex; smoking history (current/former/never); ethnicity (dichotomised as white or non-white due to the high proportion of white participants); co-morbidity; DAS28 score; HAQ score; RA duration; number of previous sDMARDs (categorised as $\leq 3$ or $\geq 4$ ); exposure to glucocorticoids at baseline; prior exposure to azathioprine (AZA); and prior exposure to cyclophosphamide (CYC). Co-morbidity was included as a composite variable constructed from presence of: hypertension; ischaemic heart disease (myocardial infarction and/or angina); stroke; lung disease (asthma, bronchitis or emphysema); renal disease; diabetes mellitus; liver disease; or depression. Registration date with the BSRBR-RA (before/after June 2004) was also included to account for other unmeasured confounding relating to temporal changes in the way that rheumatologists managed patients with RA.

Adjustment for these covariates was performed by calculating a propensity score (PS) which reflected the probability that each

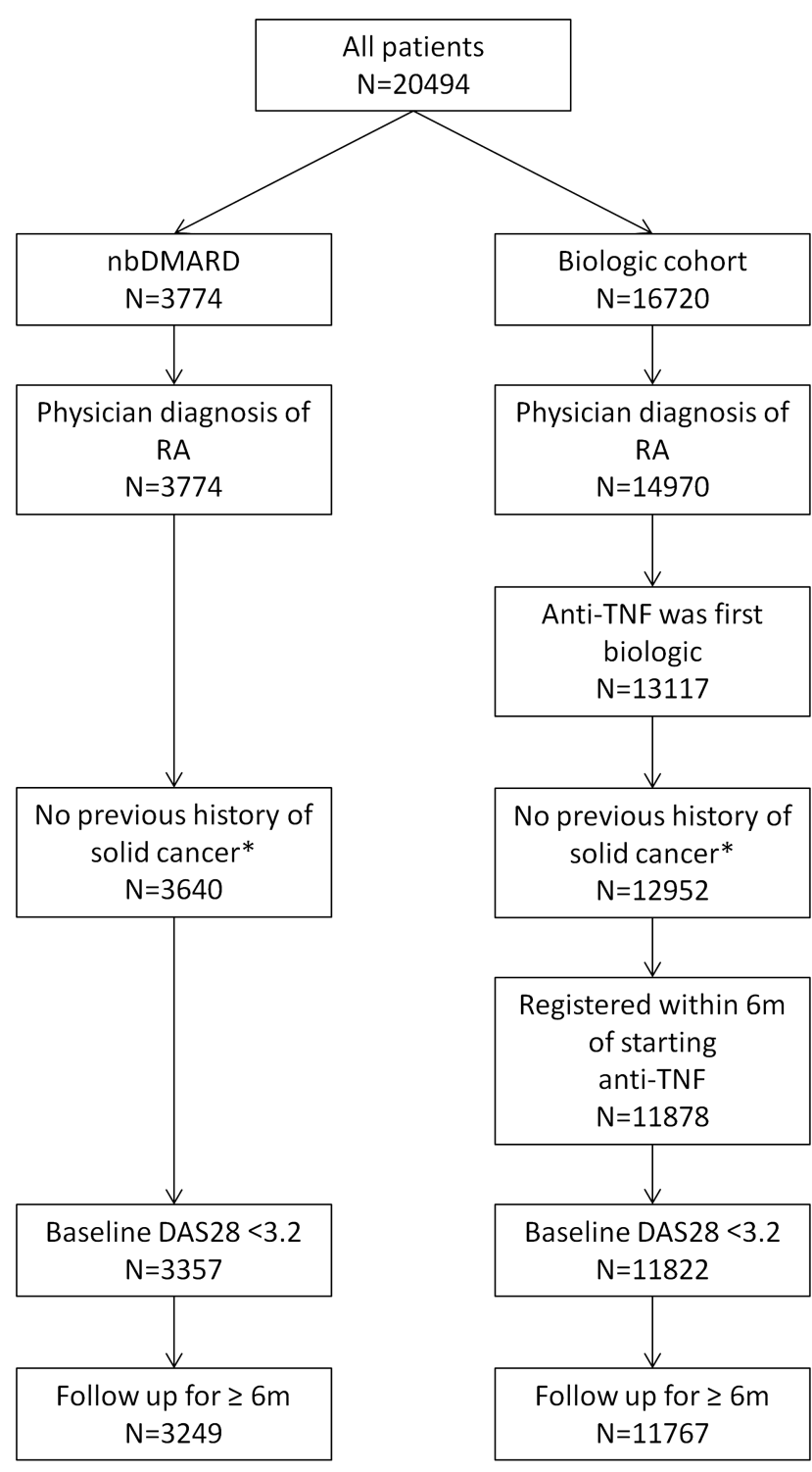

Figure 1 Selection of participants for the analysis. *As reported to the BSRBR-RA by the national cancer registries. DAS28, disease activity score; nbDMARD, non-biologic disease modifying antirheumatic drug; RA, rheumatoid arthritis; TNF, tumour necrosis factor.

patient received TNFi given their baseline characteristics. The PS has a single value for each subject that can be used in the regression model in place of all of the potentially confounding covariates. The balance of the model was tested by examining the likely bias in the treatment estimate due to each confounder. Subjects with low disease activity at baseline (DAS28 $\leq 3.2$ ) (sDMARD: 283; TNFi: 56) were excluded from the analysis in order to ensure positivity in the PS model. The PS was stratified into deciles (PD). Missing baseline data were replaced using multiple imputation (see online only supplementary methods). The assumption of proportionality was tested using Schoenfeld residuals. Stata V.12.1 was used.

\section{Drug exposure models}

The primary analysis compared patients ever treated with TNFi to those in the sDMARD cohort-that is, subjects in the TNFi cohort were considered exposed from first dose until the end of follow-up. Four sensitivity analyses were performed. First, time at risk in the TNFi cohort was restricted to time on drug or within 90 days of the first missed dose. Second, cumulative time on TNFi (plus a 90-day 
lag window) was calculated for every participant in the TNFi cohort. This cumulative exposure time was then categorised into $<1.5$ years, $1.5-3$ years and $\geq 3$ years and compared to sDMARD using Cox regression. For these sensitivity analyses, patients were censored at the date of their last received nurse-completed questionnaire since information about current drug exposure came from these questionnaires. Third, all follow-up time was included, rather than omitting the first 6 months. Finally, an analysis restricted to cancers reported by the cancer registries was performed.

The risk of first solid cancer for each TNFi agent was compared separately to sDMARDs. In these analyses, cancers were attributed to the most recently received TNFi-that is, patients contributed follow-up time to their first TNFi to the point of switching, after which follow-up and cancers were attributed to the most recent drug only. Histology reports and ICD-10 codes reported by the cancer registries were used to determine cancer sites. Site-specific analyses were performed for sites with at least 10 cancers in each cohort.

\section{Outcome following cancer diagnosis}

Mortality following cancer diagnosis was compared between patients ever exposed to TNFi and the sDMARD cohort by using Cox regression, adjusted for age as a time varying covariate and sex. Deaths were identified by record linkage with the national death registry. Deaths occurring up to 31 January 2012 were included-that is, one year after the last day of follow-up for cancer diagnosis.

\section{RESULTS}

A total of 3249 sDMARD and 11767 TNFi patients were included (figure 1). The sDMARD cohort was older and comprised more men (table 1). The TNFi cohort had more severe disease of longer duration and greater exposure to glucocorticoids and prior sDMARDs, including AZA and CYC.

A total of 563 cancers were diagnosed during 64221 patientyears of follow-up (136 in 11672 patient-years in the sDMARD and 427 in 52549 patient-years in the TNFi cohorts) (table 2). More than $90 \%$ of cancers in both cohorts were reported by the national cancer agencies. The proportion of cancers reported on the nurse questionnaire was higher in the TNFi cohort (table 2). A further 89 cancers were reported to the BSRBR (sDMARD 22; TNFi 67) but were not verified, and so were excluded from the analysis.

The unadjusted HR for TNFi compared to sDMARDs was 0.70 (95\% CI 0.58 to 0.85 ) (table 2). Age, male gender, white ethnicity, smoking, co-morbidity, RA severity, prior exposure to $\geq 4$ sDMARDs, and CYC were associated with risk of cancer in univariate analyses (see online supplementary table S2). After

Table 1 Baseline characteristics of the cohorts

\begin{tabular}{|c|c|c|c|c|c|}
\hline & \multirow{2}{*}{$\begin{array}{l}\text { SDMARD } \\
\mathrm{N}=3249\end{array}$} & \multirow{2}{*}{$\begin{array}{l}\text { All TNFi } \\
\text { N=11 } 767\end{array}$} & \multicolumn{3}{|c|}{ First TNFi drug } \\
\hline & & & $\begin{array}{l}\text { ETA } \\
\mathrm{N}=4073\end{array}$ & $\begin{array}{l}\text { INF } \\
\mathrm{N}=3457\end{array}$ & $\begin{array}{l}\text { ADA } \\
\mathrm{N}=4237\end{array}$ \\
\hline Mean age: years (SD) & $60(12)$ & $56(12)$ & $56(12)$ & $56(12)$ & $56(12)$ \\
\hline Female: $\%$ & $2381(73)$ & $8977(76)$ & $3150(77)$ & $2614(76)$ & $3213(76)$ \\
\hline \multicolumn{6}{|l|}{ Smoking history (\%) } \\
\hline Current smoker & $770(24)$ & $2569(22)$ & $834(22)$ & $756(22)$ & $979(23)$ \\
\hline Former smoker & $1276(39)$ & $4466(38)$ & $1551(38)$ & $1309(38)$ & $1606(38)$ \\
\hline Never smoked & $1188(37)$ & $4656(40)$ & $1661(41)$ & $1374(40)$ & $1621(38)$ \\
\hline Not recorded & $14(0)$ & $76(1)$ & $27(1)$ & $18(1)$ & $31(1)$ \\
\hline \multicolumn{6}{|l|}{ Ethnicity (\%) } \\
\hline White & $2459(76)$ & $9725(83)$ & $3380(83)$ & $2798(81)$ & $3547(84)$ \\
\hline Other & $62(2)$ & 407 (3) & $141(3)$ & $126(4)$ & $140(3)$ \\
\hline Not recorded & $728(22)$ & $1635(14)$ & $552(14)$ & $533(15)$ & $550(13)$ \\
\hline Mean DAS28 (SD) & $5.3(1.1)$ & $6.6(1.0)$ & $6.6(0.9)$ & $6.6(1.0)$ & $6.5(1.0)$ \\
\hline Mean HAQ (SD) & $1.5(0.7)$ & $2.0(0.6)$ & $2.1(0.6)$ & $2.1(0.5)$ & $1.9(0.6)$ \\
\hline Median disease duration: years (IQR) & $6(1,15)$ & $11(6,19)$ & $12(6,19)$ & $12(6,19)$ & $10(5,18)$ \\
\hline Baseline steroid use: $(\%)$ & $726(22)$ & $5190(44)$ & $1949(48)$ & $1596(46)$ & $1645(39)$ \\
\hline Number of prior sDMARDs: median (IQR) & $2(1,3)$ & $4(3,5)$ & $4(3,5)$ & $4(3,5)$ & $3(3,4)$ \\
\hline \multicolumn{6}{|l|}{ Co-morbidity* $(\%)$} \\
\hline None & $1358(42)$ & $5466(46)$ & $1840(45)$ & $1626(47)$ & $2000(47)$ \\
\hline 1 co-morbidity & $1123(35)$ & $4043(34)$ & $1388(34)$ & $1212(35)$ & $1443(34)$ \\
\hline 2 co-morbidities & $535(16)$ & $1662(14)$ & $616(15)$ & 470 (14) & $576(14)$ \\
\hline$\geq 3$ co-morbidities & $233(7)$ & $596(5)$ & $229(6)$ & $149(4)$ & $218(5)$ \\
\hline \multicolumn{6}{|l|}{ Year of registration (\%) } \\
\hline Pre-2003 & $7(0)$ & $1410(12)$ & $203(5)$ & $1177(34)$ & $30(1)$ \\
\hline 2003 & $279(9)$ & $2070(26)$ & $1498(37)$ & $1102(32)$ & $470(11)$ \\
\hline 2004 & $752(23)$ & $3227(27)$ & $1951(48)$ & $495(14)$ & 781 (18) \\
\hline 2005 & 797 (25) & 1613 (14) & $418(10)$ & $346(10)$ & $849(20)$ \\
\hline 2006 & $668(21)$ & $1125(10)$ & $2(0)$ & $272(8)$ & $851(20)$ \\
\hline 2007 & $331(10)$ & $843(7)$ & $1(0)$ & $65(2)$ & 777 (18) \\
\hline 2008-2009 & $415(13)$ & 479 (4) & $0(0)$ & $0(0)$ & $479(11)$ \\
\hline
\end{tabular}


Table 2 Association between exposure to TNFi and development of new solid cancer

\begin{tabular}{|c|c|c|}
\hline & $\begin{array}{l}\text { SDMARD } \\
\mathrm{N}=3249\end{array}$ & $\begin{array}{l}\text { TNFi } \\
\mathrm{N}=11767\end{array}$ \\
\hline \multicolumn{3}{|l|}{ Ever-exposed to TNFi model } \\
\hline Total follow-up time (patient-years) & 11672 & 52549 \\
\hline Follow-up per subject; median (IQR) & $4.1(2.3,5.0)$ & $5.0(4.4,5.0)$ \\
\hline Cancers & 136 & 427 \\
\hline \multicolumn{3}{|l|}{ Sources of reporting of solid cancers } \\
\hline Cancer registry (\%) & $126(93)$ & $399(93)$ \\
\hline Consultant/nurse (\%) & $83(61)$ & $322(75)$ \\
\hline Patient (\%) & $23(17)$ & 79 (19) \\
\hline Incidence rate per 10000 patient-years $(95 \% \mathrm{Cl})$ & 117 (98 to 138) & 81 (74 to 89$)$ \\
\hline Unadjusted HR $(95 \% \mathrm{Cl})$ & Referent & 0.70 (0.58 to 0.85$)$ \\
\hline Age and sex adjusted $\mathrm{HR}(95 \% \mathrm{Cl})$ & Referent & $0.91(0.75$ to 1.11$)$ \\
\hline PD adjusted HR $(95 \% \mathrm{Cl})$ & Referent & 0.83 (0.64 to 1.07$)$ \\
\hline \multicolumn{3}{|l|}{ On TNFi (plus 90 days)* } \\
\hline Follow-up time (patient-years) & 10275 & 39173 \\
\hline Cancers & 106 & 285 \\
\hline PD adjusted HR (95\% Cl) & Referent & $0.81(0.60$ to 1.10$)$ \\
\hline \multicolumn{3}{|l|}{ Cumulative exposure to TNFi } \\
\hline \multicolumn{3}{|l|}{$<1.5$ years } \\
\hline Follow-up time (patient-years) & 10275 & 20264 \\
\hline No. solid cancers & 106 & 166 \\
\hline PD adjusted HR $(95 \% \mathrm{Cl})$ & Referent & $0.87(0.66$ to 1.15$)$ \\
\hline \multicolumn{3}{|l|}{1.5 to $<3$ years } \\
\hline Follow-up time (patient-years) & 10275 & 14729 \\
\hline No. solid cancers & 106 & 99 \\
\hline PD adjusted HR $(95 \% \mathrm{Cl})$ & Referent & $0.85(0.63$ to 1.17$)$ \\
\hline PD adjusted HR $(95 \% \mathrm{Cl}) ;<1.5$ years referent & & 0.91 (0.67 to 1.24$)$ \\
\hline \multicolumn{3}{|l|}{$\geq 3$ years } \\
\hline Follow-up time (patient-years) & 10275 & 13969 \\
\hline No. solid cancers & 106 & 100 \\
\hline PD adjusted HR $(95 \% \mathrm{Cl})$ & Referent & 0.77 (0.58 to 1.03$)$ \\
\hline PD adjusted HR $(95 \% \mathrm{Cl}) ;<1.5$ years referent & & 0.77 (0.58 to 1.02$)$ \\
\hline \multicolumn{3}{|l|}{ All follow-up time (including first 6 months) } \\
\hline Follow-up time (patient-years) & 13425 & 58437 \\
\hline Cancers & 166 & 449 \\
\hline Incidence rate per 10000 patient-years $(95 \% \mathrm{Cl})$ & 124 (106 to 144$)$ & 77 (70 to 84$)$ \\
\hline PD adjusted HR $(95 \% \mathrm{Cl})$ & Referent & $0.77(0.60$ to 0.98$)$ \\
\hline \multicolumn{3}{|l|}{ Cancer registry reported cancers only } \\
\hline Follow-up time (patient-years) & 11758 & 52549 \\
\hline Cancers & 126 & 399 \\
\hline Incidence rate per 10000 patient-years $(95 \% \mathrm{Cl})$ & 107 (89 to 128$)$ & 76 (69 to 84$)$ \\
\hline PD adjusted HR $(95 \% \mathrm{Cl})$ & Referent & $0.86(0.66$ to 1.13$)$ \\
\hline
\end{tabular}

fully adjusting, using PD, there was no difference in the risk of cancer for TNFi compared to sDMARD exposed patients (adjHR $0.83,95 \%$ CI 0.64 to 1.07 ; table 2). A total of 285 solid cancers occurred while the patient was actively receiving a TNFi (or within 90 days of the first missed dose). The PD adjusted HR for TNFi was 0.81 (95\% CI 0.60 to 1.10$)$. There was no change in the PD adjusted HR with alternative exposure models or when the outcome was restricted to cancers reported by the cancer agencies (table 2). There was also no observed difference in adjusted rates when looking at each TNFi separately (table 3).

There was no significant difference in proportion or relative risk (RR) for any of the most common site specific cancers (table 4 and see online supplementary table S3), although there was a suggestion of a possible reduction in the risk of breast and colorectal cancers in the TNFi cohort.

\section{Outcome following cancer diagnosis}

Among the 563 patients with solid cancer, 309 patients died during subsequent follow-up; sDMARD 77 (57\%); TNFi 232 (54\%). Mortality was similar between the two cohorts and approximately linear (figure 2). For patients who died, the median survival time from date of cancer diagnosis was 118 days (IQR 6-342). There was no difference in the age and sex-adjusted risk of death between the two cohorts (HR 0.90, $95 \%$ CI 0.70 to 1.17$)$.

\section{DISCUSSION}

Our study found no statistically significant difference in the risk of solid cancers in patients treated with TNFi compared to those treated with sDMARDs only, after adjusting for confounders. This confirms the findings from other European biologics 
Table 3 Comparison of risk of individual TNFi therapies with sDMARD therapy

\begin{tabular}{|c|c|c|c|}
\hline & $\begin{array}{l}\text { ETA } \\
\mathrm{N}=4073\end{array}$ & $\begin{array}{l}\text { INF } \\
N=3457\end{array}$ & $\begin{array}{l}\text { ADA } \\
N=4327\end{array}$ \\
\hline Follow-up time (patient-years) & 22146 & 12379 & 18027 \\
\hline Follow-up per subject in years: median (IQR) & $4.8(2.5,5.0)$ & $3.9(1.3,5.0)$ & $3.5(2.0,4.8)$ \\
\hline Solid cancers & 190 & 98 & 139 \\
\hline Incidence rate per 10000 patient-years $(95 \% \mathrm{CI})$ & 86 (74 to 99$)$ & 79 (64 to 96$)$ & 77 (65 to 91$)$ \\
\hline Unadjusted HR $(95 \% \mathrm{Cl})^{*}$ & $0.74(0.59$ to 0.92$)$ & $0.68(0.53$ to 0.88$)$ & $0.67(0.53$ to 0.84$)$ \\
\hline Age and sex adjusted HR (95\% CI) & $1.00(0.80$ to 1.25$)$ & 0.87 (0.67 to 1.12$)$ & $0.84(0.66$ to 1.07$)$ \\
\hline PD-adjusted HR (95\% Cl) & $0.89(0.67$ to 1.19$)$ & $0.81(0.59$ to 1.11$)$ & $0.79(0.59$ to 1.05$)$ \\
\hline
\end{tabular}

registers, ${ }^{8} 912$ and from observational studies in North America. ${ }^{10} 11$ This study adds value to the existing knowledge base because it included longer exposure time and more cancers in the TNFi-treated cohort than the previous European studies, ${ }^{8} 912$ and more rigorous data collection methods than the American study. ${ }^{11}$ Data from the national cancer registries as well as from hospital records and patients were used to identify and verify cancers. The results were consistent following various adjustments and sensitivity analyses. There was also no evidence of change in risk of solid cancer with increasing exposure to TNFi. This is therefore the largest and most robust study to date of the relationship between TNFi exposure and the risk of solid cancer in patients with RA.

The size of the BSRBR-RA dataset means that this analysis had sufficient power to investigate the RR of cancer for individual TNFi compared to sDMARD. The power to detect a $50 \%$ increased risk compared to sDMARD was 99\% for ETA, $96 \%$ for INF and $98 \%$ for ADA. No difference in risk was found, and the 95\% CI for each drug did not include a relative increased risk of more than 20\%. Although the Swedish biologics register has reported no increased risk of cancer for individual TNFi, their analysis was not sufficiently powered to rule out clinically important differences: for example, the RR for ADA versus sDMARD was 1.32 (95\% CI 0.87 to 1.98$){ }^{8}$

The most frequently reported cancer sites were lung, breast, colorectal, female reproductive and gastro-oesophageal. There was no difference in the risk of either lung or gastrooesophageal cancer between the cohorts. The site-specific results align well with some, ${ }^{9}{ }^{18}$ but not all ${ }^{11}{ }^{12}$ existing evidence. Of note was a non-significant reduction in the observed

Table 4 Incidence and risk of individual solid cancer subtypes

\begin{tabular}{|c|c|c|c|c|c|}
\hline & $\begin{array}{l}\text { sDMARD } \\
\mathrm{N}=3249\end{array}$ & $\begin{array}{l}\text { TNFi } \\
N=11767\end{array}$ & $\begin{array}{l}\text { ETA } \\
\mathrm{N}=4073\end{array}$ & $\begin{array}{l}\text { INF } \\
\mathrm{N}=3457\end{array}$ & $\begin{array}{l}\text { ADA } \\
N=4327\end{array}$ \\
\hline \multicolumn{6}{|l|}{ Lung cancer } \\
\hline Number & 40 & 103 & 49 & 25 & 29 \\
\hline Incidence rate per 10000 patient-years $(95 \% \mathrm{Cl})$ & 34 (24 to 47$)$ & 20 (16 to 24$)$ & 22 (16 to 29$)$ & 20 (13 to 30$)$ & 16 (11 to 23$)$ \\
\hline Unadjusted HR $(95 \% \mathrm{Cl})$ & Referent & 0.57 (0.40 to 0.82$)$ & 0.64 (0.42 to 0.98$)$ & 0.59 (0.36 to 0.97$)$ & 0.49 (0.29 to 0.76$)$ \\
\hline Age and sex adjusted $\mathrm{HR}(95 \% \mathrm{Cl})$ & Referent & $0.81(0.56$ to 1.17$)$ & $0.95(0.62$ to 1.46$)$ & $0.81(0.49$ to 1.35$)$ & 0.64 (0.40 to 1.04$)$ \\
\hline PD-adjusted HR (95\% Cl) & Referent & 0.85 (0.52 to 1.39$)$ & $1.02(0.58$ to 1.76$)$ & $0.92(0.50$ to 1.71$)$ & $0.69(0.39$ to 1.23$)$ \\
\hline \multicolumn{6}{|l|}{ Female breast cancer } \\
\hline Number & 22 & 73 & 30 & 18 & 25 \\
\hline Incidence rate per 10000 patient-years $(95 \% \mathrm{Cl})$ & 34 (20 to 48$)$ & 18 (14 to 22$)$ & 17 (11 to 23$)$ & 19 (10 to 28$)$ & 17 (10 to 23$)$ \\
\hline Unadjusted HR $(95 \% \mathrm{Cl})$ & Referent & $0.72(0.45$ to 1.17$)$ & $0.70(0.40$ to 1.22$)$ & $0.76(0.41$ to 1.42$)$ & $0.74(0.42$ to 1.31$)$ \\
\hline Age adjusted $\mathrm{HR}(95 \% \mathrm{Cl})$ & Referent & 0.83 (0.51 to 1.35$)$ & $0.83(0.47$ to 1.45$)$ & 0.86 (0.46 to 1.61$)$ & 0.83 (0.47 to 1.48$)$ \\
\hline PD-adjusted HR (95\% Cl) & Referent & $0.58(0.32$ to 1.06$)$ & $0.56(0.28$ to 1.10$)$ & $0.59(0.28$ to 1.24$)$ & $0.59(0.31$ to 1.15$)$ \\
\hline \multicolumn{6}{|l|}{ Colorectal cancer } \\
\hline Number & 19 & 43 & 16 & 10 & 17 \\
\hline Incidence rate per 10000 patient-years $(95 \% \mathrm{Cl})$ & 16 (9 to 25$)$ & $8(6$ to 11$)$ & 7 (4 to 12$)$ & $8(4$ to 15$)$ & $9(5$ to 15$)$ \\
\hline Unadjusted HR (95\% Cl) & Referent & $0.52(0.30$ to 0.89$)$ & $0.46(0.24$ to 0.90$)$ & $0.50(0.23$ to 1.07$)$ & 0.59 (0.31 to 1.14$)$ \\
\hline Age and sex adjusted $\mathrm{HR}(95 \% \mathrm{Cl})$ & Referent & 0.71 (0.41 to 1.23$)$ & $0.66(0.33$ to 1.29$)$ & 0.67 (0.31 to 1.44$)$ & 0.79 (0.41 to 1.52$)$ \\
\hline PD-adjusted HR (95\% Cl) & Referent & $0.51(0.24$ to 1.06$)$ & 0.45 (0.19 to 1.05$)$ & $0.47(0.19$ to 1.20$)$ & 0.57 (0.26 to 1.27$)$ \\
\hline \multicolumn{6}{|l|}{ Gastro-oesophageal cancer } \\
\hline Number & 12 & 20 & 8 & 5 & 7 \\
\hline Incidence rate per 10000 patient-years $(95 \% \mathrm{Cl})$ & 10 (5 to 18$)$ & $4(2$ to 6$)$ & $4(2$ to 7$)$ & $4(1$ to 9$)$ & $4(2$ to 8$)$ \\
\hline Unadjusted HR $(95 \% \mathrm{Cl})$ & Referent & $0.35(0.17$ to 0.73$)$ & NR & NR & NR \\
\hline Age and sex adjusted $\mathrm{HR}(95 \% \mathrm{Cl})$ & Referent & $0.51(0.24$ to 1.05$)$ & NR & NR & NR \\
\hline PD-adjusted HR (95\% Cl) & Referent & 0.59 (0.23 to 1.52$)$ & NR & NR & NR \\
\hline
\end{tabular}




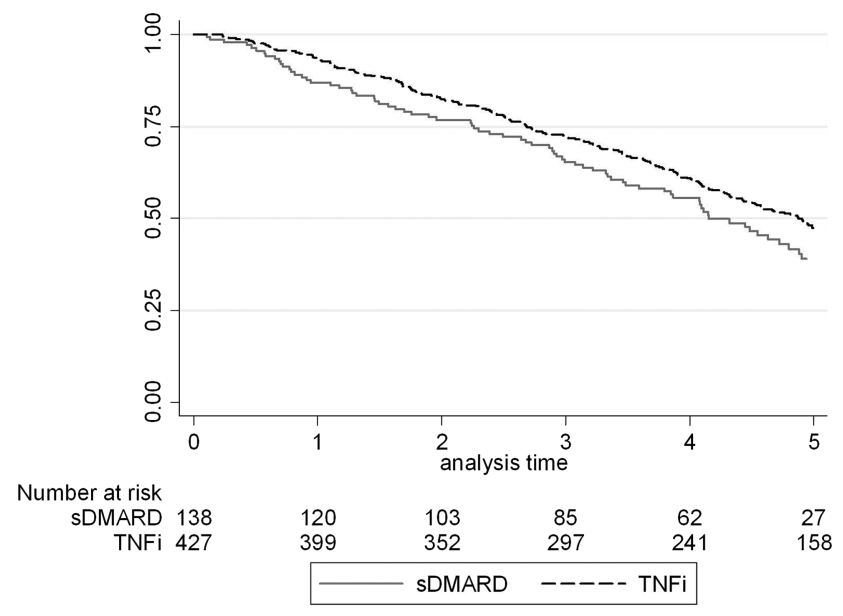

Figure 2 Kaplan-Meier survival curves for death following diagnosis with solid cancer in the BSRBR-RA. sDMARD, synthetic disease modifying antirheumatic drug; TNFi, tumour necrosis factor inhibitor.

risk of breast and colorectal cancer, also observed in the German and Swedish biologic registers. ${ }^{9}{ }^{18}$ A recent publication from the BSRBR-RA reported that the rates of both breast and colorectal cancers in the sDMARD cohort were the same as in the general population (standardised incidence ratios 1.07 (95\% CI 0.72 to 1.52 ) and 0.96 (95\% CI 0.56 to 1.54$)$ respectively), ${ }^{19}$ in contrast to other biologic-naïve cohorts in which reduced risks have been reported. ${ }^{18}{ }^{20-22}$ The signals for a reduced RR of breast cancer could reflect either unmeasured differences in subjects selected for TNFi or sDMARDs, or a true protective effect of the drug. TNF, within the microenvironment of breast cancer, has been shown to be associated with increased tumour invasiveness and poor prognosis, ${ }^{23}$ and so it is plausible that blocking the effects of TNF may slow or prevent the progression of breast cancer. However, TNF may inhibit breast cancer cell adhesion and proliferation. ${ }^{24}$ Etanercept has been trialled in the treatment of advanced metastatic breast cancer, ${ }^{25}$ although no objective disease responses were seen.

One reason for observing a reduced risk of breast cancer and colorectal cancer following TNFi might be screening prior to starting therapy, thus excluding cancers that would otherwise have been diagnosed during follow-up. However it is not routine practice to recommend such screening and this seems an unlikely explanation. Non-steroidal anti-inflammatory drugs (NSAIDs) have also been linked to reductions in breast ${ }^{26} 27$ and colon cancer. ${ }^{28}$ However, data concerning ongoing NSAID use in this cohort were not captured and thus could not be accounted for in our analyses. In contrast to this study, a Danish study reported an increased risk of colon cancer in patients treated with TNFi versus unexposed patients (HR 3.52, 95\% CI 1.11 to 11.15$){ }^{12}$ They hypothesised that this may be due to the TNFi cohort being more sedentary.

No statistically significant difference in overall survival following cancer diagnosis was observed between the cohorts. A study from the Swedish biologics register has addressed this question previously. ${ }^{29}$ They found no difference in the risk of dying between 302 RA patients who developed cancer while being treated with TNFi and 586 biologic-naïve RA matched controls who developed cancer (HR for TNFi 1.1, 95\% CI 0.8 to 1.6). Although the BSRBR-RA did not collect information on tumour stage at the time of diagnosis, the Swedish study found tumour stage at presentation to be largely similar between the groups, although the proportion of late presentations was higher in the control cohort (29\% vs $20 \%$ stage IV), suggesting there may be a degree of surveillance bias in TNFi patients.

An 'ever-exposed' to TNFi model was selected as the primary exposure definition for TNFi because it was hypothesised that any effect of TNFi on cancer risk would be long-lasting and may operate in the latent period of a cancer. This analysis model means that patients in the TNFi cohort could have been exposed to other non-TNFi biologics prior to their incident cancer. However, alternative drug exposure models did not alter the findings.

Further complexities in the possible relationship between TNFi therapy and cancer risk exist that could not be fully accounted for in this analysis. It is possible that the overall finding of no difference in the relative incidence of solid cancer between the two cohorts was the result of risks acting in opposite directions for different cancer sites at different stages in the latent phase. Analysis by site, however, showed all four of the most common malignancies to have lower rates in the TNFi cohort compared to the sDMARD cohort.

The strengths of the study include the large size of the BSRBR-RA and detailed prospective collection of data relating to both drug exposure and outcome. Furthermore, patients registering with the sDMARD cohort were required to have active RA and be treated with sDMARDs, making them as similar as possible to the TNFi cohort. The broad inclusion criteria of the register mean that the results are more generalisable than those for RCTs. Linkage with the national cancer agencies minimised potential for bias in reporting between cohorts.

The weaknesses of the study are those of any observational study. The study findings reflect the way in which British rheumatologists selected patients for treatment with TNFi. At the time of the study, UK national guidelines listed cancer within the previous 10 years as a contraindication to $\mathrm{TNFi}^{14}$ We also excluded patients with a prior cancer, meaning that these results cannot be extrapolated to patients with a previous cancer, who have been reported on previously. ${ }^{30}$ The proportion of missing baseline data was low. To minimise bias introduced by missing baseline data, multiple imputation was used. Response rates to follow-up questionnaires were excellent; less than $1 \%$ of patients in each cohort had no returned consultant follow-up. Unmeasured confounding (eg, differences in alcohol consumption) and channelling bias remain possible since subjects were not randomised to receive TNFi. Patients considered to be at high risk for developing cancer may have been preferentially recruited to the sDMARD cohort.

\section{CONCLUSIONS}

In this registry, there was no difference in the overall risk of solid cancer in patients with RA treated with TNFi, or for any of the individual TNF inhibitors, compared to sDMARDs in the first 5 years of treatment. There was no evidence of change in risk of solid cancer with increasing exposure to TNFi. There was no difference in mortality following cancer after treatment with TNFi.

Collaborators BSRBR Control Centre Consortium: The BSRBR Control Centre Consortium consists of the following institutions (all in the UK): Antrim Area Hospital, Antrim (Dr Nicola Maiden), Cannock Chase Hospital, Cannock Chase (Dr Tom Price), Christchurch Hospital, Christchurch (Dr Neil Hopkinson), Royal Derby Hospital, Derby (Dr Sheila O'Reilly), Dewsbury and District Hospital, Dewsbury (Dr Lesley Hordon), Freeman Hospital, Newcastle-upon-Tyne (Dr lan Griffiths), Gartnavel General Hospital, Glasgow (Dr Duncan Porter), Glasgow Royal Infirmary, Glasgow (Dr R Madhok), Haywood Hospital, Stoke-on-Trent (Dr Andy Hassell), Hope Hospital, Salford (Dr R G Cooper), King's College Hospital, London (Dr Ernest Choy), Kings Mill Centre, Sutton-In Ashfield (Dr David Walsh), Chapel Allerton Hospital, Leeds (Prof Paul Emery), Macclesfield District General Hospital, Macclesfield (Dr 
Susan Knight), Manchester Royal Infirmary, Manchester (Dr lan Bruce), Musgrave Park Hospital, Belfast (Dr Allister Taggart), Norfolk and Norwich University Hospital, Norwich (Prof David Scott), Poole Hospital, Poole (Dr Paul Thompson), Queen Alexandra Hospital, Portsmouth (Dr Fiona McCrae), Royal Glamorgan Hospital, Glamorgan (Dr Rhian Goodfellow), Russells Hall Hospital, Dudley (Prof George Kitas), Selly Oak Hospital, Selly Oak (Dr Ronald Jubb), St Helens Hospital, St Helens (Dr Rikki Abernethy), Weston General Hospital, Weston-super-Mare (Dr Sandra Green), University Hospital of South Manchester/Withington Community Hospital, (Dr Paul Sanders), Withybush General Hospital, Haverfordwest (Dr Amanda Coulson), North Manchester General Hospital (Dr Bev Harrison), Royal Lancaster Infirmary (Dr Marwan Bukhari) and The Royal Oldham Hospital (Dr Peter Klimiuk).

Contributors Study concept and design: LKM, KLH and DPMS. Acquisition of data: BSRBR Control Centre Consortium. Analysis and interpretation of data: LKM, ALSL, ML, KDW, DPMS, KLH and WGD. Drafting of manuscript: LKM and KLH. All authors contributed to critical revision of the manuscript for important intellectual content and approved the article for publication.

Funding LKM was funded by the Medical Research Council, UK (grant number G0701380/1).

Competing interests The BSR commissioned the BSRBR-RA as a UK-wide national project to investigate the safety of biologic agents in routine medical practice. BSR receives restricted income from UK pharmaceutical companies, presently Abbott Laboratories, Merck, Pfizer, Roche, UCB and SOBI. This income finances a wholly separate contract between the BSR and the University of Manchester who provide and oversee the BSRBR-RA data collection, management and analysis service. The principal investigators and their team have full academic freedom and are able to work independently of pharmaceutical industry influence. All decisions concerning analyses, interpretation and publication are made autonomously of any industrial contribution.

Ethics approval The study was approved by the North-West Multicentre Research Ethics Committee.

Provenance and peer review Not commissioned; externally peer reviewed.

Open Access This is an Open Access article distributed in accordance with the terms of the Creative Commons Attribution (CC BY 3.0) license, which permits others to distribute, remix, adapt and build upon this work, for commercial use, provided the original work is properly cited. See: http://creativecommons.org/ licenses/by/3.0/

\section{REFERENCES}

1 Carswell EA, Old LJ, Kassel RL, et al. An endotoxin-induced serum factor that causes necrosis of tumors. Proc Natl Acad Sci USA 1975;72:3666-70.

2 Eggermont AM, Schraffordt KH, Klausner JM, et al. Isolated limb perfusion with tumor necrosis factor and melphalan for limb salvage in 186 patients with locally advanced soft tissue extremity sarcomas. The cumulative multicenter European experience. Ann Surg 1996;224:756-64.

3 Moore RJ, Owens DM, Stamp G, et al. Mice deficient in tumor necrosis factor-alpha are resistant to skin carcinogenesis. [erratum appears in Nat Med 1999:5:1087]. Nat Med 1999;5:828-31.

4 Knight B, Yeoh GC, Husk KL, et al. Impaired preneoplastic changes and liver tumor formation in tumor necrosis factor receptor type 1 knockout mice. J Exp Med 2000;192:1809-18.

5 Bongartz T, Sutton AJ, Sweeting MJ, et al. Anti-TNF antibody therapy in rheumatoid arthritis and the risk of serious infections and malignancies: systematic review and meta-analysis of rare harmful effects in randomized controlled trials. [see comment] [erratum appears in JAMA 2006;295:2482]. [Review] [58 refs]. JAMA 2006:295:2275-85.

6 Leombruno JP, Einarson TR, Keystone EC. The safety of anti-tumour necrosis factor treatments in rheumatoid arthritis: meta and exposure-adjusted pooled analyses of serious adverse events. [Review] [64 refs]. Ann Rheum Dis 2009;68:1136-45.

7 Askling J, Fahrbach K, Nordstrom B, et al. Cancer risk with tumour necrosis factor alpha (TNF) inhibitors: meta-analysis of randomized controlled trials of adalimumab, etanercept, and infliximab using patient level data. Pharmacoepidemiol Drug Saf 2011;20:119-30.

8 Askling J, van Vollenhoven RF, Granath F, et al. Cancer risk in patients with rheumatoid arthritis treated with anti-tumor necrosis factor alpha therapies: does the risk change with the time since start of treatment? Arthritis Rheum 2009;60:3180-9.
9 Strangfeld A, Hierse F, Rau R, et al. Risk of incident or recurrent malignancies among patients with rheumatoid arthritis exposed to biologic therapy in the German biologics register RABBIT. Arthritis Res Ther 2010;12:R5.

10 Setoguchi S, Solomon DH, Weinblatt ME, et al. Tumor necrosis factor alpha antagonist use and cancer in patients with rheumatoid arthritis. [see comment] [erratum appears in Arthritis Rheum 2006;54:3134]. Arthritis Rheum 2006;54:2757-64.

11 Wolfe F, Michaud K. Biologic treatment of rheumatoid arthritis and the risk of malignancy: analyses from a large US observational study. Arthritis Rheum 2007;56:2886-95.

12 Dreyer L, Mellemkjær L, Andersen AR, et al. Incidences of overall and site specific cancers in TNF $\alpha$ inhibitor treated patients with rheumatoid arthritis and other arthritides - a follow-up study from the DANBIO Registry. Ann Rheum Dis 2013;72:79-82.

13 Prevoo ML, Van 't Hof MA, Kuper HH, et al. Modified disease activity scores that include twenty-eight-joint counts. Development and validation in a prospective longitudinal study of patients with rheumatoid arthritis. Arthritis Rheum 1995;38:44-8.

14 Ledingham J, Deighton C, on behalf of the British Society for Rheumatology Standards GaAWG. Update on the British Society for Rheumatology guidelines for prescribing TNF\{alpha\} blockers in adults with rheumatoid arthritis (update of previous guidelines of April 2001). Rheumatology 2005; 44:157-63

15 Watson K, Symmons D, Griffiths I, et al. The British Society for Rheumatology biologics register. [Review] [6 refs]. Ann Rheum Dis 2005;64(Suppl 4):iv42-3.

16 Kirwan JR, Reeback JS. Stanford Health Assessment Questionnaire modified to assess disability in British patients with rheumatoid arthritis. Br J Rheumatol 1986:25:206-9.

17 Office for National Statistics. Cancer Statistics Registrations, England (Series MB1), No. 40, 2009. http://ons.gov.uk/ons/rel/vsob1/cancer-statistics-registrations--england--seriesmb1-/no--40--2009/index.html. 7 Sep 2011 (accessed Feb 2012).

18 Askling J, Fored CM, Brandt L, et al. Risks of solid cancers in patients with rheumatoid arthritis and after treatment with tumour necrosis factor antagonists. Ann Rheum Dis 2005;64:1421-26.

19 Mercer LK, Davies R, Galloway JB, et al. Risk of cancer in patients receiving non-biologic disease-modifying therapy for rheumatoid arthritis compared with the UK general population. Rheumatology (Oxford) 2013;52:91-8.

20 Mellemkjaer L, Linet MS, Gridley G, et al. Rheumatoid arthritis and cancer risk. Eur J Cancer 1996;32A:1753-57.

21 Parikh-Patel A, White RH. Risk of cancer among rheumatoid arthritis patients in California. Cancer Causes Control 2009;20:1001-10.

22 Gridley G, McLaughlin JK, Ekbom A, et al. Incidence of cancer among patients with rheumatoid arthritis. [see comment]. J Natl Cancer Inst 1993:85:307-11.

23 Goldberg JE, Schwertfeger KL. Proinflammatory cytokines in breast cancer: mechanisms of action and potential targets for therapeutics. [Review]. Curr Drug Targets 2010;11:1133-46.

24 Su K, Tian Y, Wang J, et al. HIF-1alpha acts downstream of TNF-alpha to inhibit vasodilator-stimulated phosphoprotein expression and modulates the adhesion and proliferation of breast cancer cells. DNA Cell Biol 2012;31:1078-87.

25 Madhusudan S, Foster M, Muthuramalingam SR, et al. A phase II study of etanercept (Enbrel), a tumor necrosis factor alpha inhibitor in patients with metastatic breast cancer. Clin Cancer Res 2004;10:6528-34.

26 Harris RE, Chlebowski RT, Jackson RD, et al. Breast cancer and nonsteroidal anti-inflammatory drugs: prospective results from the Women's Health Initiative. Cancer Res 2003;63:6096-101.

27 Khuder SA, Mutgi AB. Breast cancer and NSAID use: a meta-analysis. Br I Cancer 2001;84:1188-92.

28 Flossmann E, Rothwell PM; British Doctors Aspirin Trial and the UK-TIA Aspirin Trial. Effect of aspirin on long-term risk of colorectal cancer: consistent evidence from randomised and observational studies.[see comment]. [Review] [84 refs]. Lancet 2007;369:1603-13.

29 Raaschou P, Simard JF, Neovius M, et al. Does cancer that occurs during or after anti-tumor necrosis factor therapy have a worse prognosis? A national assessment of overall and site-specific cancer survival in rheumatoid arthritis patients treated with biologic agents. Arthritis Rheum 2011;63:1812-22.

30 Dixon WG, Watson KD, Lunt $M$, et al. Influence of anti-tumor necrosis factor therapy on cancer incidence in patients with rheumatoid arthritis who have had a prior malignancy: results from the British Society for Rheumatology biologics register. Arthritis Care Res 2010;62:755-63. 